\title{
Irreducible water saturation in snow: experimental results in a cold laboratory
}

\author{
Cécile Coléou, Bernard Lesaffre \\ Centre d'Études de la Neige, Centre National de Recherches Météorologiques, Météo-France, 38406 Saint-Martin-d'Hères Cedex, France
}

\begin{abstract}
The porosity of wet snow is often about $50 \%$; however, liquid water generally fills less than $10 \%$ of this pore volume. In order to relate the irreducible water content trapped in snow to its characteristics, we have conducted experiments in a cold laboratory. The results show that irreducible water content, expressed as per cent of mass, depends only on porosity. Experimental studies were restricted to homogeneous wet snow samples. Therefore, we can only achieve a valid result in natural snowpacks when applying to an homogeneous layer of wet snow. Nevertheless, the results may be incorporated into snow-cover energy-balance models to improve the retention and percolation predictions. The thickness of the water-saturated layer observed at the base of the sample in our experiments, was related to the ratio of the mean convex radius of curvature to dry density.
\end{abstract}

\section{INTRODUCTION}

Wet snow is a complex porous medium. The three phases of water are present and liquid interacts with the solid structure. While grain metamorphism in snow is quite well known, this is not the case for its physical properties. The purpose of this study was to quantify the irreducible liquidwater content and the thickness of the water-saturated layer in wet snow. Liquid water does not penetrate snow uniformly (Colbeck, 1979a; Marsh, 1991; Schneebeli, 1995) so, in Nature, it is difficult to find a large area of snow that is homogeneously wetted. It is also difficult to find a wet snow layer thick enough and with the desired densities and grainsizes. For these reasons, we have chosen to conduct our experiments in a cold laboratory. Natural snow was collected in the field, then prepared to obtain a desired type of grain. To obtain an homogeneous sample, the snow was wetted by complete immersion. The need to prevent the sample from freezing or melting increased the difficulty of storage and measurement.

After a description of methods and the characterization of the samples, we describe the results of our measurements of the irreducible water content and the thickness of the saturated layer for different types of grains.

\section{METHODS}

Snow was collected in the field and brought into the cold laboratory then metamorphosed to obtain different types of snow. After sifting snow into a Plexiglas box $(30 \times 30 \times 18$ $\mathrm{cm}^{3}$ ) with drainage holes drilled into the bottom (diameter: $10^{-2} \mathrm{~m}$, spacing: about $5 \times 10^{-2} \mathrm{~m}$ ), the sample was put in a larger vessel and slowly filled with water at $0^{\circ} \mathrm{C}$ to saturate fully (about 5 minutes). The vessel was then emptied by siphoning and the sides of the Plexiglas box were removed. Next, the sample was stored in an insulated box surrounded by an ice-water bath to avoid melting and freezing (Fig. 1).

After storage for several hours, which allowed drainage of the sample, the liquid water and snow reached an equilibrium state with irreducible liquid water trapped in the upper part of the snow and a saturated layer at its base

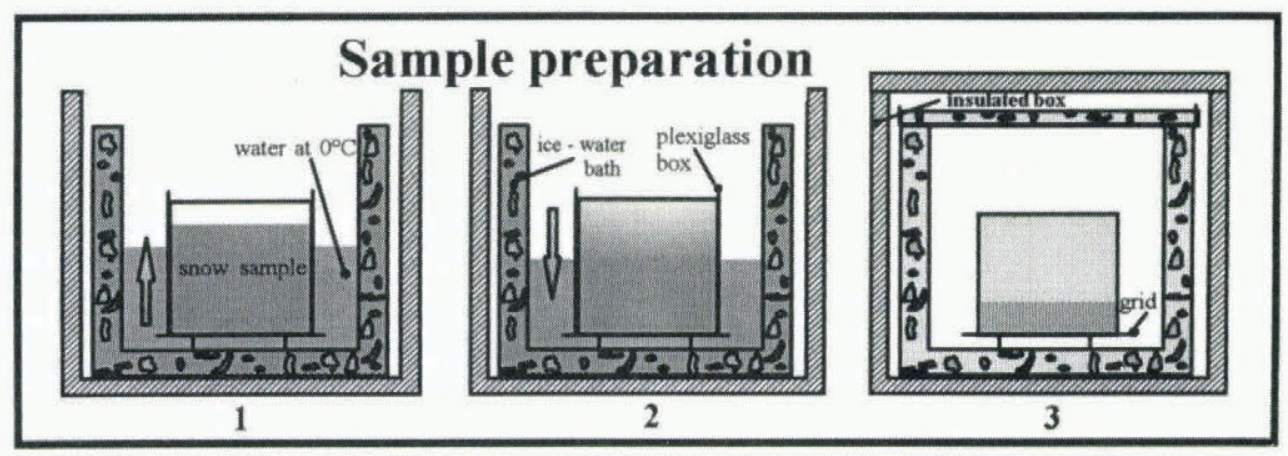

Fig. 1. Description of sample preparation: soaking a snow sample (1), siphoning (2) and storage at $0^{\circ} \mathrm{C}$ to allow drainage (3). 
(Fig. 2). At this time, liquid-water content, snow-grain morphology and the saturated layer thickness were measured to characterize the snow. For the same sample, measurements were generally done over a short period of time and subsamples were cut out at the same horizontal level.

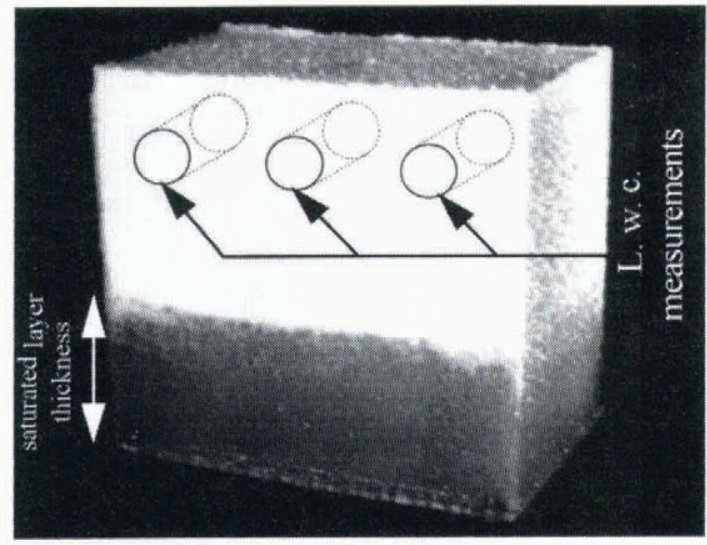

Fig. 2. A typical snow sample after soaking and draining. Irreducible liquid-water content was measured in the upper layer.

\section{Liquid-water content}

The liquid-water content was measured using a freezing calorimetry method (Jones and others, 1983). Iso-octane was the freezing agent. The calorimeter and this agent were maintained in the cold room at $-5^{\circ} \mathrm{C}$. The cold room was then warmed to about $0^{\circ} \mathrm{C}$. Pre-weighed iso-octane was poured into the calorimeter and, at the same time, a snow sample was taken out of the insulated box. Using an aluminium cylinder stored at $0^{\circ} \mathrm{C}\left(100 \mathrm{~cm}^{3}\right)$, a snow sub-sample was cut out of the sample, weighed and poured into the calorimeter. Then, the snow-iso-octane mixture was stirred to allow freezing of all the liquid water. The mass of refrozen water, i.e. the liquid-water content, was determined by measurement of the temperature variation. This method gives a precise measure of the liquid-water content (Boyne and Fisk, 1990). Measurement accuracy is $0.5 \mathrm{~g}$ water/ $100 \mathrm{~cm}^{3}$ snow.

\section{Snow-grain morphology}

The snow-grain morphology was characterized by taking a few grains from the sample, putting them on a glass slide and observing their silhouette through a microscope. A picture-analysis system, developed at the Centre d'Études de la Neige (Brun and others, 1987), computes the mean convex radius of curvature from about 40 grains. Due to soaking of the snow samples, grains from the unsaturated wet snow and the saturated layer were wet grains, according to the International Classification (Colbeck and others, 1990). Grain coarsening is rapid in liquid-saturated snow, mean grain volume increases at a constant rate which is (5-6) $\times 10^{-3} \mathrm{~mm}^{3} \mathrm{~h}^{-1}$ (Raymond and Tusima, 1979). Since the pore space of a sample was filled with water, at least for a short time, dramatic changes occurred in grain-size, especially for the initially small grains, and grain shape. Metamorphism rapidly leads to well-rounded grain contours. So the radius of curvature is well representative of grain-size.
Here, "snow grain" refers to the individual grain, the particle comprising a single crystal. In wet snow, another important characterization parameter is the size of grain clusters. When the snow is wetted, but more precisely when the water runs off, the grains are inclined to aggregate in groups or clusters, due to an increase in the capillary forces (Colbeck, 1979b). Unfortunately, the technique we used to characterize grain-size does not allow measurement of cluster size. The characterization of grains required that they be frozen. The grains were isolated as well as possible on a glass slide but we could not distinguish refrozen liquid connections from the ice bonds of clusters.

\section{Saturated layer thickness}

The thickness of the saturated layer at the base of the sample was also measured. It varied from 1 to $11 \mathrm{~cm}$. When possible, density and liquid-water content were also determined for the saturated layer.

One of the difficulties of these experiments was to determine the time that a sample needed to remain isocaloric to allow for drainage without a phase change. A high water flow was observed at the bottom of the snow shortly after its removal from the water. 2 hours later the water flow had become much lower. Measurements taken during the first hours indicated that an equilibrium was reached after 4 hours for any type of snow. Indeed run-off goes on at a very low rate, probably due to snow metamorphism. After 2 days, a decrease and a scattering of the liquid-water content (l.w.c.) measurements was observed. This decrease was probably due to side effects. The sides of the sample are in contact with air at $0^{\circ} \mathrm{C}$ in the isolated box. This air-snow interface modifies the l.w.c. distribution in its neighbourhood. Moreover, the efficiency of the isocaloric device was sometimes doubtful (sides of some samples, stored for a long time, were slightly refrozen). For intervals less than 2 days, these modifications are limited and measurements made a few centimetres from the side were not affected.

Our experiments were performed between 4 and 30 hours after the beginning of drainage. It was necessary to use several samples to determine the time of drainage, since the calorimetry method is destructive. An improvement in the investigation of percolation should use a less destructive method, for instance time-domain reflectometry.

\section{Snow-sample characterization}

Thirteen samples were studied (Fig. 3). Six samples were composed of small grains $(\mathrm{Al}-\mathrm{A} 6)$, six other samples consisted of large grains (B1-B3: depth hoar; B4-B6: wet grains), B7 was a mixture of small and large grains. The preparation of the samples and their characterization before soaking are given in the five first columns of Table 1. After the preparation stage, most of the samples were sifted into the Plexiglas box, except samples B2 and B3 which were prepared directly on the grid (bottom of the box) in order to preserve the depth-hoar texture.

In order to sieve samples B4 and B5 easily, the refrozen wet grains were lightly wetted with a warming system, using the dielectric properties of snow (Brun and others, 1988). The sifted sample was kept at $0^{\circ} \mathrm{C}$ for 2 days before wetting. All the samples were soaked with water at $0^{\circ} \mathrm{C}$ except sample B6 which was already filled with water for 4 days.

Grain-shape symbols used in Table 1 are defined in the International Classification (Colbeck and others, 1990). 

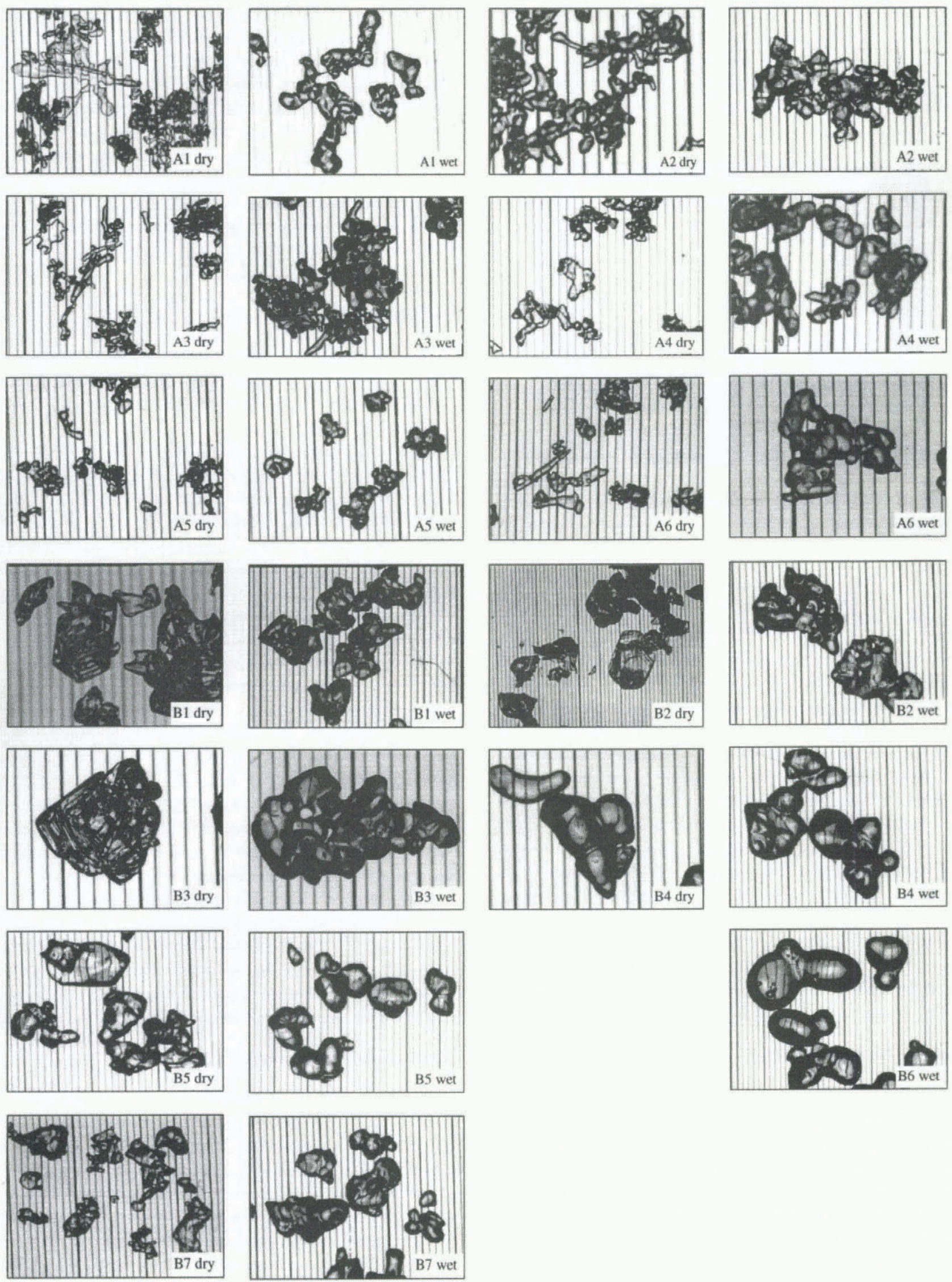

Fig. 3. Snow grains from each sample, before (dry) and after (wet) soaking. The distance between the two light black lines is $0.2 \mathrm{~mm}$.

Initial snow density was deduced from the weight of the whole sample.

\section{EXPERIMENTAL RESULTS}

The last five columns of Table 1 give values of measurements for each sample. Variations in density were observed for a few samples. These variations were produced during the sifting of snow and due to interaction with the sides of the box (snow was more dense in the middle). They had an effect on liquid-water content and the limit of the saturated layer was slightly higher in the middle of the sample. 
Table 1. Table of measurements for each sample. m.c.r. is the mean convex radius of the grains

\begin{tabular}{|c|c|c|c|c|c|c|c|c|c|}
\hline \multirow[b]{2}{*}{$\begin{array}{l}\text { Sample } \\
\text { number }\end{array}$} & \multirow{3}{*}{$\begin{array}{c}\text { Snow } \\
\text { preparation }\end{array}$} & \multicolumn{3}{|c|}{$\begin{array}{l}\text { Initial snow characteristics } \\
\text { just before soaking }\end{array}$} & \multicolumn{3}{|c|}{ Unsaturated wet snow } & \multicolumn{2}{|c|}{ Water-saturated layer } \\
\hline & & $\begin{array}{l}\text { Grain } \\
\text { shape }\end{array}$ & m.c.r. & Density & m.c.r. & l.w.c. & Density & Thickness & m.c.r. \\
\hline & & & $\times 10^{3} \mathrm{~m}$ & $\mathrm{~kg} \mathrm{~m}^{3}$ & $\times 10^{3} \mathrm{~m}$ & $\%$ per mass & $\mathrm{kg} \mathrm{m}^{-3}$ & $\mathrm{~cm}$ & $\times 10^{3} \mathrm{~m}$ \\
\hline $\mathrm{Al}$ & (1) Stored 1 week at $-18^{\circ} \mathrm{C}$ & $1+$ & 0.13 & 235 & $\begin{array}{l}0.19 \\
0.19 \\
0.19\end{array}$ & $\begin{array}{l}11.5 \\
11.9 \\
12.4\end{array}$ & $\begin{array}{l}381 \\
362 \\
365\end{array}$ & 5 & 0.29 \\
\hline $\mathrm{A} 2$ & Prepared as for sample $\mathrm{Al}$ & 11 & 0.15 & 268 & $\begin{array}{l}0.19 \\
0.19 \\
0.19\end{array}$ & $\begin{array}{l}12.8 \\
13.4 \\
12.7\end{array}$ & $\begin{array}{l}368 \\
359 \\
379\end{array}$ & 5 & 0.26 \\
\hline A3 & (1) Stored 1 month at $-18^{\circ} \mathrm{C}$ & 11 & 0.14 & 269 & $\begin{array}{l}0.19 \\
0.19 \\
0.19\end{array}$ & $\begin{array}{l}10.9 \\
12.1 \\
10.7\end{array}$ & $\begin{array}{l}380 \\
372 \\
382\end{array}$ & 5 & 0.27 \\
\hline A4 & $\begin{array}{l}\text { (1) Stored } 2 \text { months at }-18^{\circ} \mathrm{C} \\
\text { then sifted a first time }\end{array}$ & $1 \bullet$ & 0.16 & 339 & $\begin{array}{l}0.19 \\
0.19 \\
0.19\end{array}$ & $\begin{array}{l}9.8 \\
9.6 \\
9.7\end{array}$ & $\begin{array}{l}426 \\
429 \\
424\end{array}$ & $7-7.5$ & 0.29 \\
\hline A5 & $\begin{array}{l}\text { (1) Stored } 1 \text { month at }-18^{\circ} \mathrm{C} \text { then } \\
\text { crushed to increase density. }\end{array}$ & $\bullet$ & 0.16 & 400 & $\begin{array}{l}0.19 \\
0.19\end{array}$ & $\begin{array}{l}6.7 \\
6.6\end{array}$ & $\begin{array}{l}503 \\
500\end{array}$ & 9 & 0.30 \\
\hline A6 & Prepared as for sample A5 & $\bullet$ & 0.14 & 410 & $\begin{array}{l}0.19 \\
0.19 \\
0.19\end{array}$ & $\begin{array}{l}7.6 \\
6.7 \\
6.4\end{array}$ & $\begin{array}{l}509 \\
513 \\
505\end{array}$ & 11 & 0.28 \\
\hline $\mathrm{Bl}$ & $\begin{array}{l}\text { (1) Exposed to a large temperature } \\
\text { gradient for several days }\end{array}$ & $\wedge \wedge$ & 0.24 & 380 & $\begin{array}{l}0.29 \\
0.29\end{array}$ & $\begin{array}{l}8.7 \\
9.1\end{array}$ & $\begin{array}{l}465 \\
458\end{array}$ & 5.5 & 0.32 \\
\hline B2 & Prepared as for sample Bl & $\wedge \wedge$ & 0.28 & 265 & $\begin{array}{l}0.29 \\
0.29 \\
0.31\end{array}$ & $\begin{array}{l}14.7 \\
14.4 \\
13.9\end{array}$ & $\begin{array}{l}328 \\
338 \\
341\end{array}$ & 1.5 & 0.44 \\
\hline B3 & Prepared as for sample $\mathrm{Bl}$ & $\wedge \wedge$ & 0.21 & Unknown & $\begin{array}{l}0.26 \\
0.26 \\
0.26 \\
0.27 \\
0.27\end{array}$ & $\begin{array}{l}12.2 \\
12.8 \\
11.9 \\
12.7 \\
12.8\end{array}$ & $\begin{array}{l}365 \\
347 \\
363 \\
345 \\
349\end{array}$ & 2 & 0.43 \\
\hline B4 & $\begin{array}{l}\text { (2) Lightly wetted with a warming } \\
\text { system. }\end{array}$ & $\mathrm{OO}$ & 0.35 & 480 & $\begin{array}{l}0.39 \\
0.39 \\
0.38\end{array}$ & $\begin{array}{l}7.3 \\
6.6 \\
7.4\end{array}$ & $\begin{array}{l}478 \\
542 \\
473\end{array}$ & $3-3.5$ & 0.46 \\
\hline B5 & As for B4 then sifted & $\mathrm{OO}$ & 0.30 & 515 & 0.32 & 5.0 & 584 & $6-6.5$ & 0.38 \\
\hline B6 & $\begin{array}{l}\text { As for } \mathrm{Bl} \text { then soaked } 4 \text { days in } \\
\text { water at } 0^{\circ} \mathrm{C}\end{array}$ & OO & Unknown & Unknown & $\begin{array}{l}0.56 \\
0.56 \\
0.56\end{array}$ & $\begin{array}{l}7.0 \\
7.1 \\
7.1\end{array}$ & $\begin{array}{l}543 \\
534 \\
531\end{array}$ & $2-2.5$ & 0.62 \\
\hline B7 & $\begin{array}{l}\text { (2) Crushed in order to obtain a } \\
\text { mixture of large and small } \\
\text { grains }\end{array}$ & $\mathrm{O} \bullet$ & 0.25 & 580 & $\begin{array}{l}0.26 \\
0.29 \\
0.30\end{array}$ & $\begin{array}{l}5.5 \\
5.3 \\
5.8\end{array}$ & $\begin{array}{l}581 \\
589 \\
561\end{array}$ & 7.5 & 0.39 \\
\hline
\end{tabular}

(1) Recently deposited snow collected in the field.

(2) Wet grains collected in the field in a wet state and then frozen for storage.

\section{Irreducible liquid-water content}

In the following paragraphs, $W_{\mathrm{m}}$ is the liquid-water content expressed as per cent of mass, $W_{\mathrm{p}}$ is the liquid-water content expressed as per cent of pore volume, and $W_{\mathrm{mi}}$ and $W_{\mathrm{pi}}$ are their respective irreducible values.

Figure 4 shows a curve for all experiments which illustrates the linearity of $W_{\mathrm{mi}}$ with $P /(1-P)$ where $P$ is snow porosity.

The equation of the regression is: $W_{\mathrm{mi}}=0.0057 /$ $(1-P)+0.017$ with a correlation coefficient of 0.98 .

The term $P /(1-P)$ is equal to the ratio of pore volume to ice volume. It only varies with the dry density of snow (ratio of ice mass to total volume of snow) and not with grain-size. When density was high $P /(1-P) \sim 0.9$, irreducible l.w.c. was observed to be about $7 \%$ of the mass both in small grains (samples A5 and A6) and in the largest ones (samples B4 and B6). In the same way, forlowerdensity snow $P /(1-P) \sim 1.8$, 1.w.c. was about $12 \%$ of the mass for Al, A2 and B3. For sample
$\mathrm{B} 7$, the mean convex radius was not representative of grainsize because this sample was a mixture of large and fine grains; however l.w.c. measurements still fit on the curve.

$W_{\mathrm{p}}$ can be expressed in terms of $W_{\mathrm{m}}$ and $P$, as:

$$
W_{\mathrm{p}}=\frac{W_{\mathrm{m}}}{P /(1-P)} \times \frac{d_{\mathrm{i}} / d_{\mathrm{w}}}{\left(1-W_{\mathrm{m}}\right)}
$$

where $d_{\mathrm{i}}$ is ice density and $d_{\mathrm{w}}$ is water density. In our experi-

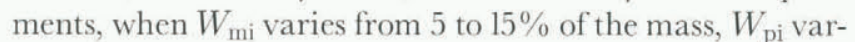
ies from 6.5 to $8.5 \%$ of pore volume (e.g. for $P=0.5$, the regression gives $W_{\mathrm{pi}}=7.3 \%$ ). This result agrees with previous experiments by Colbeck (1974) which suggest that the irreducible water content of dense snow is $W_{\mathrm{pi}}=7 \%$ of pore volume.

Experimental conditions were restrictive from natural conditions so that may limit the results in their application to natural snowpacks. The samples studied were always prepared as homogeneously as possible, using the same structure (grid/saturated layer/unsaturated wet snow), without 


\section{Irreducible liquid-water content}

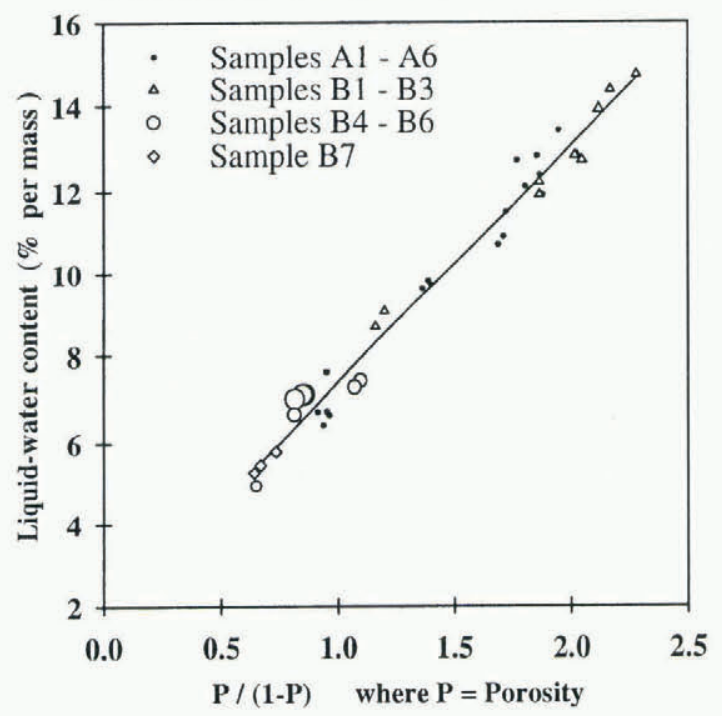

Fig. 4. Irreducible liquid-water content vs $P /(1-P)$ for all experiments. The symbol shape represents the grain shape before wetting; the symbol size is related to the wet-grain size.

melt-freeze cycles. Moreover, the measurements were always taken within the same time range after the beginning of drainage. Since a large range of initial grain shapes and densities was studied, snow texture was not taken into account and was probably less variable than for wet snow in a natural snow pack.

\section{Thickness of the water-saturated layer in snow}

In each experiment, a water-saturated layer appears at the bottom of the sample. Its thickness varies from 1 to $11 \mathrm{~cm}$. The upper limit of this layer was neither sharp nor straight (Fig. 2). In these layers, density was about $900-950 \mathrm{~kg} \mathrm{~m}^{-3}$ and l.w.c. is near $50 \%$ of the mass.

Figure 5 shows the thickness of the water-saturated layer plotted vs the ratio of mean convex radius (m.c.r.) to dry density. Due to the limited thickness of some samples, it was not possible to measure density systematically. In a first approach, the dry density used was measured in the unsatu-

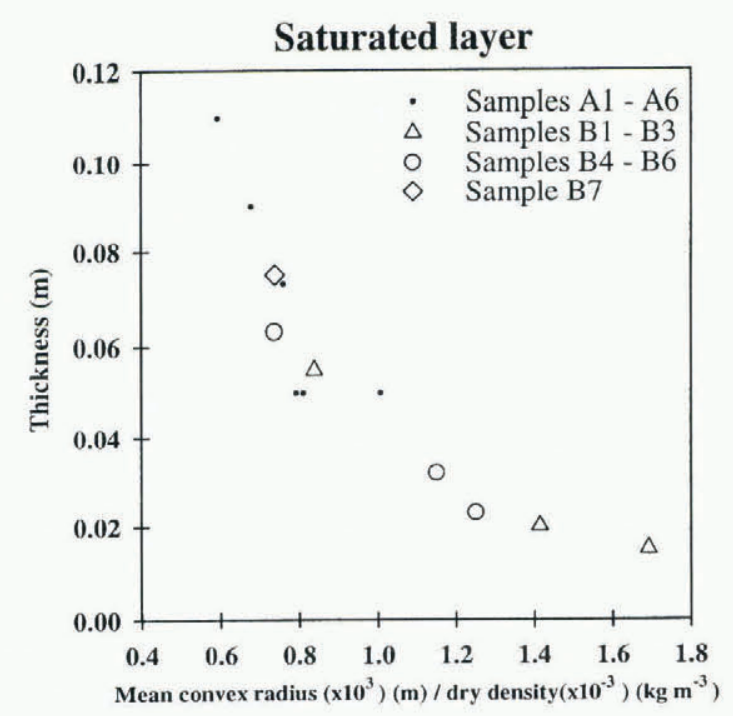

Fig. 5. Thickness of saturated layer vs the ratio of mean convex radius to dry density for each sample. rated layer but only when measurements were done less than 6 hours after the beginning of drainage.

The m.c.r. was determined using the picture analysis system mentioned previously, on grains taken from the saturated layer.

Thickness of the saturated layer increased as the ratio m.c.r./dry density decreased. This thickness is related to the height of capillary rise. Snow is a porous medium, at a first approximation, and can be considered as a group of capillary tubes. Snow with large grains and low density will correspond to large pores, whereas small grains at high density will correspond to very fine pores where water can go up or stay higher. Grain-size and density give information on pore size. The next step will be to observe pore size directly by using sectioning techniques and relate it to capillary rise.

\section{CONCLUSION}

Measurements on different types of snow were conducted in a cold laboratory. We paid particular attention to investigating a large range of densities and grain-sizes. Experiments on homogeneous wet snow samples show that the irreducible liquid-water content per unit mass in wet snow depends only on the dry density of snow not on the grain-size. Irreducible liquid-water content, expressed as per cent of mass, varies linearly with the ratio of pore volume to ice volume.

These results may be incorporated into snow-cover energy-balance models to improve retention and percolation predictions.

Furthermore, measurements of the thickness of the water-saturated layer observed at the bottom of a wet snow sample suggests that it varies inversely with the ratio of the mean convex radius of grain curvature to dry density. This ratio could be representative of pore size as observed in thin sections. As this thickness is related to the height of capillary rise, more experiments will be conducted in order to discover a relationship to pore size.

\section{REFERENCES}

Boyne, H. S. and D. J. Fisk. 1990. A laboratory comparison of field techniques for measurement of the liquid water fraction of snow. CRREL Spec. Rep. 90-3.

Brun, E. 1989. Investigation on wet-snow metamorphism in respect of liquid-water content. Ann. Glaciol., 13, 22-26.

Brun, E., F. Touvier and G. Brugnot. 1987. Experimental study on thermal convection and grains picture analysis. In Jones, H. G. and W. J. OrvilleThomas, eds. Seasonal snowcovers: physics, chemistry, hydrology. Dordrecht, etc., D. Reidel Publishing Co., 75-94. (NATO ASI Series C: Mathematical and Physical Sciences 211.)

Colbeck, S. C. 1974. The capillary effects on water percolation in homogeneous snow. J. Glaciol., 13 (67), 85-97.

Colbeck, S. C. 1979a. Grain clusters in wet snow. J. Colloid Interface Sci., 72(3), 371-384.

Colbeck, S. C. 1979b. Water flow through heterogeneous snow. Cold Reg. Sci. Technol., 1 (1), 37-45.

Colbeck, S. C. and 7 others. 1990. The international classification for seasonal snow on the ground. Wallingford, Oxon, International Association of Scientific Hydrology. International Commission on Snow and Ice.

Jones, E. B., A. Rango and S. M. Howell. 1983. Snowpack liquid water determinations using freezing calorimetry. Nord. Hydrol., 14 (3), 113-126.

Marsh, P. 1991. Water flux in melting snow covers. In Corapcioglu, M.Y., ed. Advances in porous media. Vol.1. New York, Elsevier Science Publishers, 61-124.

Raymond, C. F. and K. Tusima. 1979. Grain coarsening of water-saturated snow. F. Glaciol., 22 (86), 83-105.

Schneebeli, M. 1995. Development and stability of preferential flow paths in a layered snowpack. International Association of Hydrological Sciences Publication 228 (Symposium at Boulder 1995 - Biogeochemistry of Seasonally Snow-Covered Catchments), 89-95. 